\title{
Altın, Gümüş ile BİST Madencilik Endeksi Getirileri Arasındaki Volatilite Etkileşiminin Diagonal VECH GARCH Modeliyle Analizi
}

\author{
DOI: 10.26466/opus.905547
}

\author{
$*$ \\ Hüseyin Bașar Önem* \\ * Dr. Öğr. Üyesi, Isparta Uygulamalı Bilimler Üniversitesi, Isparta MYO, Isparta/ Türkiye \\ E-Posta: basaronem@isparta.edu.tr \\ ORCID: $\underline{0000-0003-0192-2886}$
}

\begin{abstract}
Öz
Altın uzun zamandır yatırım aracı olarak kullanılan ve yatırımcıların ilgisini çeken bir finansal varlık iken gümüş son yıllarda daha fazla oranda yatırmmcilarm dikkatini çekmekte ve portföylerinde yer almaktadır. Gerek ülke ekonomilerinde gerekse küresel finans piyasalarında finansal yatırım araçlar arasında etkileşim çok hızlı bir şekilde artmaktadır ve bu araçlar arasında önemli bir ilişki mevcuttur. Bu çalışmada altın ve gümüş fiyat getirileri ile BISST Madencilik Endeksi getirisi arasındaki volatilite etkileşiminin ortaya konulması amaçlanmaktadır. Bu amaçla altın ve gümüş fiyatları ile BİsT Madencilik Endeksi arasındaki, volatilite etkileşimini ölçmek için, 01.02.2017-01.02.2021 tarihleri arasında günlük verilerin baz alındığı çalışmada, Augmented Dickey-Fuller birim kök testi ile durağanlık sınaması yapılmış ve Diagonal VECH GARCH Modeli kullanılmıştır. Analiz sonuçlarına göre BISTT Madencilik Endeksi getirisi ile altın ve gümü̈ş fiyat getirilerinde yoğun volatilitile kümelenmeleri görülmekte olup bu getirilerde volatilitenin sürekli ve kalıcı etkilere sahip olduğu bulunmuştur. Ayrıca altın ve gümüş fiyatlarının volatilitelerini arttıran şoklar BISST Madencilik Endeksi volatilitesini azaltmaktadır. Buna göre altın ve gümüş fiyatlarından BİST Madencilik Endeksi fiyatlarma doğru bir volatilite etkileşimi bulunmaktadır.
\end{abstract}

Anahtar Kelimeler: Altın Fiyatları, Gümüş Fiyatları, BISST Madencilik Endeksi, Volatilite, Diagonal VECH GARCH Modeli. 


\title{
Analysis of Volatility Interaction between Gold, Silver and BIST Mining Index Returns with Diagonal VECH GARCH Model
}

\begin{abstract}
While gold is a financial asset that has been used as an investment tool for a long time and attracts the attention of investors, silver has been attracting the attention of investors in recent years and is included in their portfolios. The interaction between financial investment instruments is increasing rapidly both in national economies and in global financial markets, and there is an important relationship between these instruments. In this study, it is aimed to reveal the volatility interaction between gold and silver price returns and BIST mining index return. For this purpose, in order to measure the volatility interaction between gold and silver prices and BIST mining index, in the study based on daily data between 01.02.2017 and 01.02.2021, the Augmented Dickey-Fuller unit root test was used and the Diagonal VECH GARCH Model was used. According to the results of the analysis, intense volatility clusters are seen in the BIST mining index return and gold and silver price returns, and it has been found that volatility has continuous and permanent effects on these returns. In addition, shocks that increase the volatility of gold and silver prices reduce the volatility of the BIST mining index. Accordingly, there is a volatility interaction from gold and silver prices to BIST mining index prices.
\end{abstract}

Keywords: Gold Prices, Silver Prices, BIST Mining Index, Volatility, Diagonal VECH GARCH Model. 


\section{Giriş}

Finans piyasalarında küreselleşmenin etkisiyle sürekli ve önemli değişiklikler meydana gelmiştir. Bu değişiklikler sermayeye ilişkin kısıtlamaların kaldırılması ile özellikle yükselen ve gelişmiş ekonomileri etkilemiştir (Gopal ve Munusamy, 2016, s.41). Ekonomik birimlerin ekonomiye yönelik beklentileri ile ekonomik değişkenler arasında yakın bir ilişki olduğu 1970'li yıllardan bu yana ekonomi biliminin içine yerleşmiş bir konudur. Bu nedenle ülkelerin çeşitli kurumları ekonomik birimlerin beklentilerini ölçmeye yönelik çalışmalar yapmaktadırlar. (Gökalp, 2019, s.140)

Altın, 1971'den beri piyasada emtia olarak kullanılmaktadır (Baig, Shahbaz, Imran, Jabbar ve Ain, 2013, s.28). Altın uzun zamandır mal ve para yerine kullanılmış ve altına yönelik yatırımcıların ilgisi her dönem önemli olmuştur. Aynı zamanda modern para sistemlerinin oluşmasında da, bir güvence ya da dayanak olarak kullanılan altın, gün geçtikçe çeşitli alternatiflerin ortaya çıkmasına rağmen, önemli bir yatırım aracı olma statüsünü devam ettirmektedir. Bundan dolayı, altın fiyatı volatilitesinin hesaplanması çok önemlidir (Karabacak, Meçik ve Genç, 2014, s.81). Altın, olağanüstü özellikleri nedeniyle güvenli bir geri dönüş yatırımı olarak dünyadaki en değerli emtia olmuştur. Altın fiyatlarının davranışını incelemek ve geliştirmek çok faydalı olacaktır ( Senaviratna ve Cooray, 2017, s.100).

Gümüş, değerli bir metaldir. Gümüşün spot fiyatı yalnızca mevcut durumu yansıtmaz, aynı zamanda arz ve talep koşulllarının yanı sıra yatırımcıların gelecekteki enflasyon beklentilerini de yansıtmaktadır (Harper, Jin, Sokunle ve Wadhwa, 2013, s.2). Gümüşün dünya üzerinde sınırlı bir kaynak olduğu tartışılamayacak bir gerçektir. İnsanların kullandığı ilk para birimi olan gümüş, her zaman oldukça nadir olması ve tedarik süresinin kısa olmasından dolayı, bir değer ölçütü olarak hizmet etmiştir ( Sverdrup, Koca ve Ragnarsdottir, 2014, s.121).

Altın ve gümüş, yaygın olarak kullanılan değerli metallerdir. Bu metaller standart parasal değişim araçlarıdır ve büyük menkul kıymetler borsalarında kağıt veya kaydileştirilmiş hisse senedi formunda işlem görmektedirler (Mahato ve Attar, 2014, s.1). Tarih boyunca, altın ve gümüş, kıymetli metaller olarak birbirleri ile yakından ilişkili roller 
oynamışlardır ve yatırımcıların portföylerinde güvenli liman terimiyle bulundurduğu yatırım araçlarındandır. Ayrıca, altın ve gümüş fiyatları arasında uzun vadeli rasyonel karşılıklı bir ilişkinin olduğu da tartışılabilir ( Ciner, 2001, s.299).

Zaman serilerinde görünen ani artış ve azalışlar şeklinde açıklanan belirsizlik kavramı iktisadi ve finansal kararları etkileyen önemli unsurlardan biridir (Erdoğan ve Bozkurt, 2009, s.145). Makroekonomik unsurlarda tahmin edilemeyen ani artış ya da azalışlar (oynaklık), varyansın değişmesine sebep olur. Literatürde ARCH kavramı açılanmadan önce, meydana gelen ani değişiklikler değişkenlik olgusu ile aynı anlamda kullanılmaktaydı. Ancak koşullu varyans olgusunun çıkmasıyla birlikte, serilerdeki tahmin edilemeyen ani değişimler, bir başka açıdan seriye ilişkin belirsizlik, koşullu varyansla açılanan oynaklık olgusu ile açıklanmaya başlanmıştır (Bozkurt, 2009, s.126).

Finansal zaman serilerinin volatilite kümelenmesi, aşırı basıklık ve kaldıraç etkisi gibi sabit varyans varsayımını ortadan kaldıran unsurlara sahip olmalarından dolayı literatürde volatilite modellemesi için yüksek miktarlarda koşullu değişen varyansları temel alan ARCH/GARCH modelleri kullanılmıştır. Değişkenler arasındaki volatilite yayılımının bulunabilmesi için ise literatürde en sık kullanılan modeller çok değişkenli koşullu değişen varyans modelleri olan Multi-GARCH modelleridir (Yaman ve Korkmaz, 2020, s.682).

Bu çalışmada, altın, gümüş fiyat getirileri ile BİST Madencilik Endeksi getirileri arasındaki volatilite yayılım etkisinin ekonometrik yöntemlerle belirlenmesi amaçlanmıştır. Bu amaç doğrultusunda çalışmanın teorik bilgilerinin verildiği giriş bölümünün ardından altın, gümüş fiyatları getirileri ile BİST Madencilik Endeksi getirileri arasındaki ilişkileri inceleyen ulusal ve uluslararası literatür incelemesinin yer aldığı literatür bölümü oluşturulmuştur. Daha sonra analizde kullanılacak yöntemden bahsedilmiş olup en son araştırma bulguları ve sonuç kısmı ile çalışma tamamlanmıştır. 


\section{Literatür}

Erol ve Aytekin (2020), çalışmalarında altın fiyatlarını etkileyen faktörler arasındaki nedensellik ilişkisini ölçmek için 01.08.2010 ile 31.03.2020 dönemi günlük verileri kapsayan altın, gümüş, platin, paladyum ons Fiyatları, BIST 100, Dow Jones, VIX korku endeksi, Brent petrol fiyat1, USD/JPY Paritesi ve ABD 10 yıllık tahvil faiz oranı değişkenleri kullanarak Granger nedensellik testini uygulamışlardır. Elde edilen bulgulara göre altın ile platin ve paladyum arasında çift yönlü nedensellik ilişkisinin bulunduğu, altından gümüş ve Dow Jones endeksine doğru ve Brent petrol ve ABD 10 yıllık tahvil faiz oranından altına doğru tek yönlü nedensellik ilişkisi bulunurken, BIST 100 endeksi, VIX korku endeksi ve USD/JPY paritesi ile altın arasında nedensellik ilişkisi bulamamiştır.

Başarır (2019), çalışmasında altın ve BIST 100 piyasası arasındaki ilişkiyi 2006 Nisan- 2018 Ağustos tarihleri arasında aylık veriler kullanarak Toda-Yamamoto nedensellik testleri ile ölçmüştür. Analiz sonuçlarına göre, altın getirisinden BIST 100 endeksine doğru bir nedensellik ilişkisi olmadığını bulmuştur.

Cicioğlu, Eraslan ve Torun (2018), çalışmalarında 2003:03 - 2016:05 tarihleri arasında altın fiyatlarının, Dow Jones Endeksi, enflasyon, BİST 100 endeksi, Reel efektif döviz kuru, gümüş ve petrol fiyatları ile ilişkisini FMOLS, DOLS ve CCR eş bütünleşme testleri ve basit regresyon modeli ile analiz etmişlerdir. Eş bütünleşme testlerine göre BİST'deki değişmeler altın fiyatlarını negatif etkilerken, gümüş fiyatları ve Amerikan borsasındaki değişmeler altın fiyatlarını pozitif etkilemektedir. Regresyon analizine göre ise BİST, Amerikan Borsası ve gümüş fiyatlarındaki değişmelerin altın fiyatları üzerinde etkisi bulunurken, diğer değişkenlerin etkisi bulunamamıştır.

Gazel (2018), çalışmasında Mart-1999 ile Ekim-2016 tarihleri arasında altın, gümüş ve platin ile BIST 100 endeksi, faiz oranı ve döviz kuru arasındaki uzun dönemli ilişkiyi, Fourier eşbütünleşme testi ile araştırmıştır. Elde edilen bulgulara göre kıymetli metaller ile makroekonomik değişkenler arasında uzun dönemli bir ilişki bulmuştur.

Deniz, Okuyan ve Sakarya (2018) çalışmalarında 1999-2018 tarihleri arasında, altının BİST hisse senedi portföylerine sağladığı çeşitlendirme 
araştırılmıştır. Analiz sonuçlarına göre hisse senetleri ile altın arasında negatif korelasyon ve negatif beta katsayısının varlığı tespit edilmiş, söz konusu negatif ilişkinin yerel ve global şok dönemlerinde artış gösterdiği görülmüştür. Aynı zamanda portföyde bulunan BİST100 endeksine çeşitli ağırlıklarda altın eklendiğinde oluşan portföyün riskinin azaldığı/Sharpe oranının arttığı sonucuna varmışlardır.

Şencan (2017), çalışmasında, BİST altın endeks getiri volatilitesi için model oluşturulması amacıyla 1 Ağustos 2012 ve 13 Ekim 2015 tarihleri arasındaki günlük BİST altın endeks kapanış değerlerini kullanarak en uygun koşullu değişen varyans modelinin $\mathrm{GARCH}(1,1)$ yöntemi olduğunu belirlemiştir.

Vveinhardt, Streimikiene, Ahmed, Ghauri ve Ashraf (2017), çalışmalarında, 1 Ocak 2010- 30 Haziran 2016 tarihleri arasındaki günlük veri seti ile ham petrol ve altın fiyatlarının Baltık ülkelerinin ve Güney Asya borsaları hisse senedi getirileri üzerindeki etkisini araştırmışlardır. Analizde Johansen eşbütünleşme testi ve Granger nedensellik testi uygulanmış olup, Johansen eşbütünleşme testi sonuçlarına göre, incelenen ekonomik göstergeler arasında eşbütünleşmenin olmadığ1 sonucuna ulaşılmıştır. Ayrıca Granger Nedensellik testine göre değişkenler arasında nedensellik ilişkisi tespit edememişlerdir.

Eyüboğlu ve Eyüboğlu (2016), çalışmalarında 2003: 5-2014: 12 tarihleri arasında altın, gümüş ve bakır fiyatlarının Borsa İstanbul'da işlem gören ve madencilik sektöründe faaliyet gösteren 6 şirketin hisse senedi fiyatları üzerindeki etkisini Johansen eşbütünleşme testi ve EKK ile incelemiştir. Analiz sonuçlarına göre IHMAD, IPEKE, KOZAA ve PRKME hisse senedi fiyatları ile altın, gümüş ve bakır fiyatları arasında uzun dönemli ilişki bulunamamıştır. En küçük kareler yöntemine göre; bakır fiyatlarının IHMAD hisse senedi fiyatlarını negatif yönde, altın fiyatlarının ise IPEKE ve KOZAA hisse senedi fiyatları üzerinde pozitif yönde etkisinin olduğu belirlenmiştir.

Aijaz, Faisal ve Meraj (2016), çalışmalarında Pakistan'da Ocak 1995 Aralık 2015 tarihleri arasında altın ve ham petrol fiyatlarının borsa endeksi (KSE 100 Endeksi) üzerindeki etkisini regresyon analizi yardımıyla araştırmışlardır. Elde edilen bulgular, altın fiyatının Karaçi Menkul Kıymetler Borsası 100 endeksine önemli ölçüde pozitif etkisi olduğunu 
gösterirken, ham petrol fiyatı ile Karaçi Borsası100 Endeksi arasında önemsiz pozitif bir ilişki bulmuşlardır.

Shaique, Aziz ve Herani (2016), çalışmalarında Pakistan'da Ekim 1993 - Mayıs 2014 tarihleri arasında Karaçi altın fiyatları ile KSE-100 endeksi arasındaki uzun dönem ilişkiyi Johnson Co-Integration testi ve Vector Auto-Regressive Model (VAR) kullanılarak incelemiştir. Analiz sonuçlarına göre KSE 100 endeksi ile altın fiyatları arasında uzun dönemli bir ilişki olmadığını bulmuşlardır.

Gültekin ve Hayat (2016), çalışmalarında 2005: 01-2015: 04 tarihleri arasında aylık verileri kullanarak İstanbul Altın oluşan altın fiyatları, döviz kuru, faiz oranı, TÜFE ve BİST 100 endeksi, altının ons fiyatı ve petrol fiyatı değişkenleri eşbütünleşme testleri ve VAR modeli ile incelemişlerdir. Elde edilen bulgular, İstanbul Altın Borsası'nda altın fiyatı için gelecek dönem öngörü hata varyansı içinde en büyük payın ons fiyatı ile petrol fiyatı olduğunu gösterirken, en düşük payın ise faiz oranı olduğunu göstermektedir.

Bhunia (2013), çalışmasında, Hindistan'da ham petrol fiyatı ile yurt içi altın fiyatı, döviz kurları ve hisse senedi fiyat endeksleri arasındaki eşbütünleşme ilişkilerini Johansen eşbütünleşme analizi ve Granger nedensellik testi ile araştırmıştır. Analiz sonuçlarına göre Johansen eşbütünleşme testi ile değişkenler arasında uzun vadeli bir ilişki olduğunu bulmuştur.

Baig, Shahbaz, Imran, Jabbar ve Ain (2013), çalışmalarında 2000-2010 dönemi aylık veriler kullanarak altın fiyatları, petrol fiyatları ve KSE100 getirisi arasındaki ilişkiyi Johansen ve Jelseluis Eş bütünleşme testi, Varyans Ayrıştırma testini kullanarak incelemişlerdir. Analiz sonuçlarına göre altın, petrol fiyatları ve KSE100 getirisi arasında uzun vadede önemli bir ilişki olmadığı sonucuna varmışlardır.

Patel (2012), çalışmasında Hindistan borsasında Ocak 1991'den Aralık 2011'e kadarki zaman aralığında Faiz Oranı, Enflasyon, Döviz Kuru, Sanayi Endeksi Üretim, Para Arzı, Altın Fiyatı, Gümüş Fiyatı ve Petrol Fiyatı gibi değişkenlerin Sensex ve S\&P CNX Nifty borsa endeksine etkilerini, Johansen Eşbütünleşme testi, Granger Nedensellik testi ve Vektör Hatası Düzeltme Modeli (VECM) ile araştırmıştır. Araştırma sonuçlarına göre makroekonomik değişkenlerle borsa endeksleri arasında uzun dönemli bir ilişki bulmuştur. 


\section{Yöntem}

Çalışmada Borsa İstanbul'da faaliyette bulunan BİST Madencilik Endeksi ile altın ve gümüş fiyat getirileri arasındaki volatilite etkileşimi ve aktarımı Diagonal VECH GARCH modeli ile analiz edilmiştir.

\section{Araştırmanın Modeli}

Araştırmada kullanılan Diagonal VECH GARCH modelini Engle ve Kroner, (1995)'te geliştirmişlerdir. Bu model ile ilgili bilgiler aşağıdaki gibidir.

VEC-GARCH modelinde koşullu varyans, $A_{j}$ ve $B_{j}$ $(\mathrm{N} \times(\mathrm{N}+1) / 2) \times(\mathrm{N} \times(\mathrm{N}+1) / 2)$ boyutundaki parametre matrisleri olmak üzere;

$$
\operatorname{vec}\left(\mathrm{H}_{\mathrm{t}}\right)=\mathrm{c}+\sum_{\mathrm{j}=1}^{\mathrm{q}} \mathrm{A}_{\mathrm{j}} \operatorname{vech}\left(\varepsilon_{\mathrm{t}-\mathrm{j}} \varepsilon_{\mathrm{t}-\mathrm{j}}^{\prime}\right)+\sum_{\mathrm{j}=1}^{\mathrm{P}} \mathrm{B}_{\mathrm{j}} \operatorname{vech}\left(\mathrm{H}_{\mathrm{t}-\mathrm{j}}\right)
$$

şeklinde ifade edilmektedir. Burada, vech (.) simetrik bir $\mathrm{N} \times \mathrm{N}$ boyutlu matrisin alt üçgensel bölgede kalan kısmını $(\mathrm{N} \times(\mathrm{N}+1) / 2) \times 1$ boyutlu bir vektöre çeviren matematiksel operatörü temsil etmektedir. (Songül, 2010, s.22)

Matris formunda ifade edilecek olursa, dışsal etkiler taşımayan iki değişkenli bir VEC-GARCH(1,1) modeli; (Engle ve Kroner, 1995, s.125)

$$
\left[\begin{array}{l}
h_{11, t-1} \\
h_{12, t-1} \\
h_{22, t-1}
\end{array}\right]
$$

$\mathrm{h}_{\mathrm{t}}=\left[\begin{array}{l}\mathrm{h}_{11, \mathrm{t}} \\ \mathrm{h}_{12, \mathrm{t}} \\ \mathrm{h}_{22, \mathrm{t}}\end{array}\right]=\left[\begin{array}{l}\mathrm{c}_{1} \\ \mathrm{c}_{2} \\ \mathrm{c}_{3}\end{array}\right]+\left[\begin{array}{lll}\mathrm{a}_{11} & \mathrm{a}_{12} & \mathrm{a}_{13} \\ \mathrm{a}_{21} & \mathrm{a}_{22} & \mathrm{a}_{23} \\ \mathrm{a}_{31} & \mathrm{a}_{32} & \mathrm{a}_{33}\end{array}\right]\left[\begin{array}{c}\varepsilon^{2}{ }_{1, \mathrm{t}-1} \\ \varepsilon_{1, \mathrm{t}-1} \varepsilon_{2, \mathrm{t}-1} \\ \varepsilon^{2}{ }_{2, \mathrm{t}-1}\end{array}\right]+\left[\begin{array}{lll}\mathrm{g}_{11} & \mathrm{~g}_{12} & \mathrm{~g}_{13} \\ \mathrm{~g}_{21} & \mathrm{~g}_{22} & \mathrm{~g}_{23} \\ \mathrm{~g}_{31} & \mathrm{~g}_{32} & \mathrm{~g}_{33}\end{array}\right]+$

İki değişkenli Diagonal VECH GARCH modelini basitçe göstermek için ise şu formülü kullanırız: (Engle ve Kroner, 1995, s.126)

$$
\begin{aligned}
& \mathrm{h}_{\mathrm{t}}=\left[\begin{array}{l}
\mathrm{h}_{11, \mathrm{t}} \\
\mathrm{h}_{12, \mathrm{t}} \\
\mathrm{h}_{22, \mathrm{t}}
\end{array}\right]=\left[\begin{array}{l}
\mathrm{c}_{01} \\
\mathrm{c}_{02} \\
\mathrm{c}_{03}
\end{array}\right]+\left[\begin{array}{ccc}
\mathrm{a}_{11} & 0 & 0 \\
0 & \mathrm{a}_{22} & 0 \\
0 & 0 & \mathrm{a}_{33}
\end{array}\right]\left[\begin{array}{c}
\varepsilon^{2}{ }_{1, \mathrm{t}-1} \\
\varepsilon_{1, \mathrm{t}-1} \varepsilon_{2, \mathrm{t}-1} \\
\varepsilon^{2}{ }_{2, \mathrm{t}-1}
\end{array}\right]+\left[\begin{array}{ccc}
\mathrm{g}_{11} & 0 & 0 \\
0 & \mathrm{~g}_{22} & 0 \\
0 & 0 & \mathrm{~g}_{33}
\end{array}\right]+ \\
& {\left[\begin{array}{l}
\mathrm{h}_{11, \mathrm{t}-1} \\
\mathrm{~h}_{12, \mathrm{t}-1} \\
\mathrm{~h}_{22, \mathrm{t}-1}
\end{array}\right]}
\end{aligned}
$$


Burada gösterilen iki değişkenli modelde, her birinde üç serbest parametre vardır. $a_{1}$ ve $g_{1}$ matrislerinin ve genel $n$-değişken köşegen modelinde her matristeki $((n(n+1)) / 2)$ serbest parametrelerdir. (Engle ve Kroner, 1995, s.126)

\section{Veriler}

Borsa İstanbul'da faaliyette bulunan BİST Madencilik Endeksi ile altın ve gümüş fiyat getirileri arasındaki volatilite etkileşiminin ve aktarımının araştırıldığı çalışmada, 01.02.2017-01.02.2021 dönemlerinde ilgili endekslerin günlük kapanış değerleri kullanılmıştır. Çalışmada altın ve gümüş ile ilgili günlük fiyatlar Merkez Bankası EVDS' den (Elektronik Veri Dağıtım Sistemi) alınmış olup, BİST maden endeksi fiyatları ise Finnet 2000 Plus veri tabanından elde edilmiştir. Ayrıca tüm değişkenlerin getiri serileri oluşturulmuştur.

Altın ve gümüş fiyatları ile BİST Madencilik Endeksine ilişkin getiriler, kapanış fiyat serileri kullanılarak aşağıda yer alan sürekli getiri formülü yardımıyla hesaplanmıştır. (Yaman ve Korkmaz, 2020, s.687) $R_{t}=\operatorname{Ln}\left(P_{t} / P_{t-1}\right)$

Denklem 1'de $R_{t}$ endeks ve döviz serilerinin t günündeki getirisini, $P_{t}$ endeks ve döviz serilerinin $t$ günündeki kapanış fiyatını, $P_{t-1}$ ise serilerin t-1 günündeki kapanış fiyatını ifade etmektedir.

\section{Bulgular}

Altın, gümüş ve BİST Madencilik Endeksine ait fiyat endekslerinin getirilerine ait grafikler sırasıyla Şekil1'de sunulmuştur 
ALTN

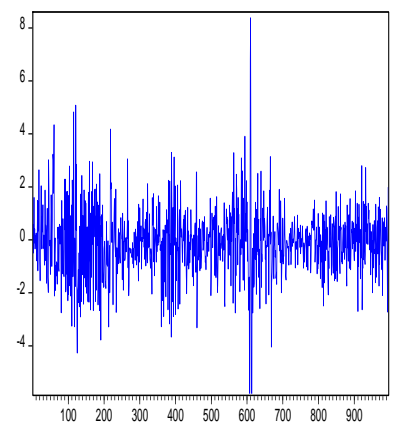

GUMS

MADEN
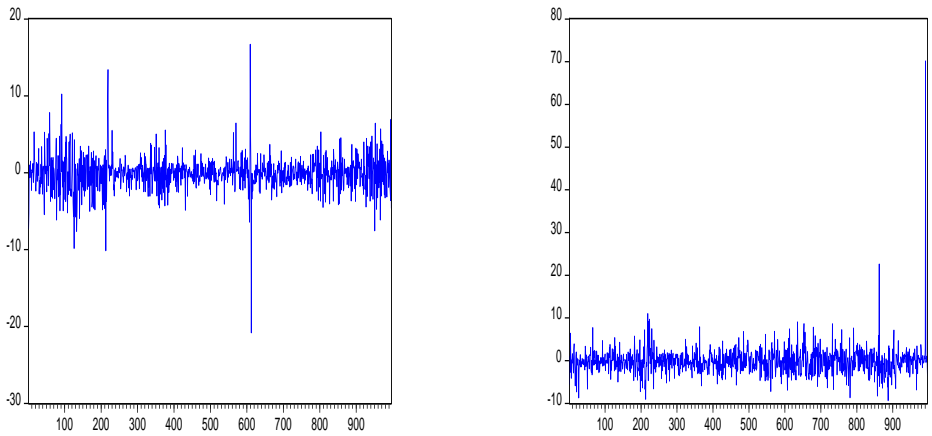

Altın, gümüş ve BİST Madencilik Endeksine ait fiyat endekslerinin getirilerine ait tanımlayıcı istatistikler tablo 1'de verilmiştir.

Tablo 1. Değişkenlerin Getiri Serilerine ait Tanımlayıcı İstatistikler

\begin{tabular}{llll}
\hline & Altın & Gümüş & BİST Maden \\
\hline Ortalama & -0.100453 & -0.095622 & -0.072763 \\
Medyan & -0.057355 & 0.000000 & -0.080455 \\
Maksimum & 8.380048 & 16.70668 & 70.16682 \\
Minimum & -10.60358 & -20.81952 & -9.354332 \\
Standart Sapma & 1.356279 & 2.307547 & 3.552308 \\
Çarpıklık & -0.440119 & -0.162271 & 8.058584 \\
Basılılı & 11.42891 & 14.60645 & 156.8469 \\
Jarque-Bera & 2980.584 & 5594.825 & 993038.8 \\
Olasılık & 0.000000 & 0.000000 & 0.000000 \\
Gözlem Sayısı & 996 & 996 & 996 \\
\hline
\end{tabular}

Tablo 1'deki değerler incelendiğinde altın, gümüş ve BİST Madencilik Endeksinin sıfıra çok yakın bir ortalamaya sahip olduğunu göstermektedir. Standart sapma değerleri altın getirileri için \%135, gümüş getirileri 
için \%230 ve BİST Madencilik Endeksinin getirileri için ise \%355 düzeyinde olmuştur.

Çalışmada kullanılan değişkenlerin durağan yapıda olması için birim kök testleri yapılır. Eğer bir veri birim kök içeriyorsa, bu durum ilgili verinin durağan olmadığı anlamına gelmektedir. Augmented DickeyFuller birim kök testi sonuçları tablo 2'de gösterilmiştir.

Tablo 2. ADF Birim Kök Testi Sonuçları

\begin{tabular}{|c|c|c|c|}
\hline \multirow[t]{3}{*}{ Değişkenler } & \multirow[t]{3}{*}{ Durağanlık seviyesi } & Augmented & \multirow{3}{*}{$\begin{array}{l}\text { Dickey-Olasılık } \\
\text { İstatistiği }\end{array}$} \\
\hline & & Fuller Test & \\
\hline & & Değeri & \\
\hline$\overline{\text { Altın }}$ & Düzey & -23.59886 & 0.0000 \\
\hline Gümüş & Düzey & -34.40621 & 0.0000 \\
\hline BİST Madencilik Endeksi & Düzey & -32.61024 & 0.0000 \\
\hline
\end{tabular}

Tablo 2'de yeralan Augmented Dickey-Fuller birim kök testi sonuçlarına göre altın, gümüş ve BİST Madencilik Endeksi değişkenlerinin düzey değerlerinde durağan olduğu görülmektedir. Birim kök testinden sonra serilerin uygun gecikme uzunlukları Akaike bilgi kriterine göre belirlenmiş olup, ilgili gecikme uzunlukları tablo 3 ve tablo 4'de gösterilmiştir.

Tablo 3. Altın ve BİST Madencilik Endeksine Ait Uygun Gecikme uzunluklarn

\begin{tabular}{lllllll}
\hline Lag & LogL & LR & FPE & AIC & SC & HQ \\
\hline 0 & -4359.158 & 4,785468 & 23.39449 & 8.828255 & $8.838165^{*}$ & $8.832023^{*}$ \\
1 & -4355.698 & 6.897913 & 23.42010 & 8.829349 & 8.859080 & 8.840655 \\
2 & -4348.142 & $15.03609^{*}$ & $23.25211^{*}$ & $8.822150^{*}$ & 8.871701 & 8.840994 \\
3 & -4345.975 & 4.302997 & 23.33856 & 8.825861 & 8.895233 & 8.852242 \\
4 & -4343.253 & 5.395121 & 23.39902 & 8.828447 & 8.917640 & 8.862366 \\
5 & -4341.501 & 3.465470 & 23.50575 & 8.832997 & 8.942010 & 8.874454 \\
6 & -4339.501 & 3.947018 & 23.60114 & 8.837046 & 8.965880 & 8.886041 \\
7 & -4339.264 & 0.465693 & 23.78167 & 8.844665 & 8.993319 & 8.901197 \\
8 & -4337.989 & 2.506004 & 23.91327 & 8.850181 & 9.018656 & 8.914251 \\
\hline
\end{tabular}

Altın ve BİST Madencilik Endeksine ait uygun gecikme uzunlukları Akaike bilgi kriterine gore 2 olarak tespit edilmiştir. 
Tablo 4. Gümüş ve BÍST Madencilik Endeksine Ait Uygun Gecikme uzunluklar

\begin{tabular}{lllllll}
\hline Lag & LogL & LR & FPE & AIC & SC & HQ \\
\hline 0 & -4873.569 & 6,546985 & 66.27536 & 9.869572 & $9.879483^{*}$ & $9.873341^{*}$ \\
1 & -4868.615 & 9.877779 & $66.14751^{*}$ & $9.867641^{*}$ & 9.897372 & 9.878948 \\
2 & -4865.675 & 5.850503 & 66.28959 & 9.869787 & 9.919338 & 9.888631 \\
3 & -4860.733 & $9.813707^{*}$ & 66.16334 & 9.867880 & 9.937252 & 9.894262 \\
4 & -4857.841 & 5.730194 & 66.31202 & 9.870124 & 9.959317 & 9.904044 \\
5 & -4853.952 & 7.691903 & 66.32694 & 9.870348 & 9.979362 & 9.911805 \\
6 & -4852.597 & 2.674006 & 66.68313 & 9.875703 & 10.00454 & 9.924698 \\
7 & -4851.527 & 2.107309 & 67.07994 & 9.881634 & 10.03029 & 9.938167 \\
8 & -4848.789 & 5.382146 & 67.25164 & 9.884189 & 10.05266 & 9.948258 \\
\hline
\end{tabular}

Gümüş ve BİST Madencilik Endeksine ait uygun gecikme uzunlukları Akaike bilgi kriterine göre 1 olarak tespit edilmiştir.

Altın ve BIST Madencilik Endeksinin getirilerine ait tahmin edilen Diagonal VECH GARCH modeli sonuçları tablo 5'de verilmiştir.

Tablo 5. Altın ve BÍST Madencilik Endeksinin Getirilerine ait Sonuçlar

\begin{tabular}{llll}
\hline & Katsayılar & t-İstatistikleri & Olasılık Değerleri \\
\hline $\mathrm{C}(1,1)$ & 0.0395448594 & 1.98917 & 0.04668285 \\
$\mathrm{C}(2,1)$ & 0.112668995 & 0.72854 & 0.46628048 \\
$\mathrm{C}(2,2)$ & 0.294362333 & 2.27473 & 0.02292208 \\
$\mathrm{~A}(1,1)$ & 0.127899595 & 5.07426 & 0.00000039 \\
$\mathrm{~A}(2,1)$ & 0.028644842 & 1.36306 & 0.17286253 \\
$\mathrm{~A}(2,2)$ & 0.058052826 & 3.55664 & 0.00037563 \\
$\mathrm{G}(1,1)$ & 0.853249158 & 26.53309 & 0.00000000 \\
$\mathrm{G}(2,1)$ & -0.887482902 & -10.07970 & 0.00000000 \\
$\mathrm{G}(2,2)$ & 0.899960665 & 29.45711 & 0.00000000 \\
\hline
\end{tabular}

Altın ve BIST Madencilik Endeksinin getirilerine ait tahmin edilen Diagonal VECH GARCH modeli sonuçlarının yer aldığ 1 Tablo 5'e göre $C(1,1), C(2,1), C(2,2)$ parametreleri sabit sayıy ifade etmektedir. $A(1,1)$ ve $G(1,1)$ parametreleri altın fiyatlarının volatilitesini açılamakta olup bu parametrelerin $\% 5$ güven seviyesinde her ikisi de anlamlı olduğu için katsayıların toplamı alındığında 0,98 sonucu çıkmaktadır. 1 sayısına çok yakın olan bu sonuç altın fiyatı getirilerinde yoğun volatilite kümelenmeleri olduğunu göstermektedir. Ayrıca altın fiyatlarında volatilite kalıcı ve sürekli etkilere sahiptir. A(2,2), G(2,2) parametreleri BİST Madencilik Endeksinin volatilitesini açıklamakta olup bu parametrelerin $\% 5$ güven seviyesinde her ikisi de anlamlı olduğu için katsayıların toplamı alındığında 0,96 sonucu çıkmaktadır. 1 sayısına çok yakın olan bu sonuç BİST Madencilik Endeksi getirilerinde yoğun volatilite kümelenmeleri 
olduğunu göstermektedir. Ayrıca BİST Madencilik Endeksinde volatilite kalıcı ve sürekli etkilere sahiptir.

$A(2,1), G(2,1)$ parametreleri de altın fiyatları getirilerinin volatilitesinin BİST Madencilik Endeksi volatilitesine etkisini ölçmektedir. İlgili tablo sonuçlarına göre $\% 5$ güven seviyesinde $A(2,1)$ parametresi anlamsız olup, $G(2,1)$ parametresi anlamlıdır. $G(2,1)$ parametresinin katsayıs1 $-0,88$ çıkmış olup bu sonuca göre altın fiyatları getirilerinin volatilitesini artıran \% 1'lik bir şok, bir sonraki işlem günü BİST Madencilik Endeksi volatilitesini \% 0,88 oranında azaltmaktadır. Buna göre altın fiyatlarından BİST Madencilik Endeksine doğru bir volatilite etkileşimi bulunmaktadir.

Gümüş ve BİST Madencilik Endeksi getirilerine ait tahmin edilen Diagonal VECH GARCH modeli sonuçları tablo 6'da verilmiştir.

Tablo 6. Gümüş̧ ve BİST Madencilik Endeksi Getirilerine ait Sonuçlar

\begin{tabular}{llll}
\hline & Katsayılar & t-İstatistikleri & Olasillk Değerleri \\
\hline $\mathrm{C}(1,1)$ & 0.082081015 & 2.41397 & 0.01577987 \\
$\mathrm{C}(2,1)$ & 0.597558939 & 2.34676 & 0.01893768 \\
$\mathrm{C}(2,2)$ & 0.261174582 & 2.17431 & 0.02968194 \\
$\mathrm{~A}(1,1)$ & 0.086702387 & 4.77622 & 0.00000179 \\
$\mathrm{~A}(2,1)$ & -0.025297377 & -0.96020 & 0.33695304 \\
$\mathrm{~A}(2,2)$ & 0.051178545 & 3.11212 & 0.00185746 \\
$\mathrm{G}(1,1)$ & 0.894983841 & 39.54844 & 0.00000000 \\
$\mathrm{G}(2,1)$ & -0.656247226 & -2.12263 & 0.03378471 \\
$\mathrm{G}(2,2)$ & 0.910955916 & 31.65907 & 0.00000000 \\
\hline
\end{tabular}

Gümüş ve BİST Madencilik Endeksi getirilerine ait tahmin edilen Diagonal VECH GARCH modeli sonuçlarının yer aldığı Tablo 6'ya göre $C(1,1), C(2,1), C(2,2)$ parametreleri sabit sayıy ifade etmektedir. $A(1,1)$ ve $G(1,1)$ parametreleri gümüş fiyatları getirilerinin volatilitesini açıklamakta olup bu parametrelerin \%5 güven seviyesinde her ikisi de anlamlı olduğu için katsayıların toplamı alındığında 0,98 sonucu çıkmaktadır. 1 sayısına çok yakın olan bu sonuç gümüş fiyatı getirilerinde yoğun volatilite kümelenmeleri olduğunu göstermektedir. Ayrıca gümüş fiyatları getirilerinde volatilite kalıcı ve sürekli etkilere sahiptir. $A(2,2), G(2,2)$ parametreleri BIST Madencilik Endeksi volatilitesini açıklamakta olup bu parametrelerin $\% 5$ güven seviyesinde her ikisi de anlamlı olduğu için katsayıların toplamı alındığında 0,96 sonucu çıkmaktadır. 1 sayısına çok 
yakın olan bu sonuç BİST maden endeksi getirilerinde yoğun volatilite kümelenmeleri olduğunu göstermektedir. Ayrıca BİST Madencilik Endeksinde volatilite kalıcı ve sürekli etkilere sahiptir.

$A(2,1), G(2,1)$ parametreleri de gümüş fiyatları getirilerinin volatilitesinin BİST Madencilik Endeksi volatilitesine etkisini ölçmektedir. İlgili tablo sonuçlarına göre $\% 5$ güven seviyesinde $A(2,1)$ parametresi anlamsız olup, $G(2,1)$ parametresi anlamlıdır. $G(2,1)$ parametresinin katsayısı $-0,65$ çıkmış olup bu sonuca göre gümüş fiyatları getirilerinin volatilitesini artıran \% 1'lik bir şok, bir sonraki işlem günü BİST Madencilik Endeksi volatilitesini \% 0,65 oranında azaltmaktadır. Buna göre gümüş fiyatlarından BİST Madencilik Endeksine doğru bir volatilite etkileşimi bulunmaktadır.

\section{Sonuç ve Öneriler}

Altın ve gümüş uzun zamandır değerli metaller olarak zihinlerde yer edinmiş olup, ödemeler dengesinde kullanılan ve yatırımcıların çok ilgisini çeken kavramlardır. Altın ve gümüşün fiyatlarında meydana gelen değişimler yatırımcılar tarafından kısa ve uzun dönemli yatırım aracı olarak kullanılmasına sebep olmuştur. Altın gerek ülke ekonomilerinde gerekse küresel dünya ekonomilerinde güvenli liman kavramı ile kendisini bağdaştırmıştır. Ayrıca altın hane halkında, işletmelerde ve devletlerde bir zenginlik ölçüsü olarak karşıllk bulmaktadır. Finansal piyasalarda önemli bir işlem hacmine sahip olan altın ve gümüş, makroekonomik değişkenler içinde yer alarak birçok finansal enstrümanı da etkilemektedir. Bu çalışmada altın ve gümüş fiyat getiri volatilitesinin BİST Madencilik Endeksi fiyat getiri volatilitesine etki düzeyi amaçlanmıştır. Çalışmada ilk olarak araştırmanın modeli kurulmuş olup daha sonra tanımlayıcı istatistikler, birim kök testi yapılmış ve ilgili değişkenler arasındaki volatiliteyi ölçmek amacıyla çok değişkenli GARC yöntemlerinden Diagonal VECH GARCH modeli kullanılmıştır. İlgili literatür incelendiğinde altın ve gümüş getirilerindeki volatilite yayılımın BİST Madencilik Endeksi volatilitesine etki düzeyinin Diagonal VECH GARCH modeli kullanarak araştııılmasına rastlanılmamıştır. Bu yüzden çalışmanın özgünlük sunabileceği ve literatüre katkı sağlaması düşünülmektedir. 
Çalışmada elde edilen bulgulara göre altın fiyatı getirilerinde, gümüş fiyatı getirilerinde ve BİST Madencilik Endeksi getirilerinde yoğun volatilite kümelenmeleri olduğu ve bu değişkenlerdeki volatilitenin kalıcı ve sürekli etkilere sahip olduğu sonucuna varılmıştır. Altın fiyatlarının volatilitesini artıran \% 1'lik bir şok, bir sonraki işlem günü BİST Madencilik Endeksi volatilitesini \% 0,88 oranında azaltmaktadır. Buna göre altın fiyatlarından BİST Madencilik Endeksine doğru bir volatilite etkileşimi bulunmaktadır. Ayrıca gümüş fiyatlarının volatilitesini artıran \% 1'lik bir şok, bir sonraki işlem günü BİST Madencilik Endeksi volatilitesini \% 0,65 oranında azaltmaktadır. Buna göre gümüş fiyatlarından BİST Madencilik Endeksine doğru bir volatilite etkileşimi bulunmaktadır.

Çalışmada elde edilen sonuçların, BİST Madencilik Endeksi hisse senedini elinde bulunduran ve yatırım yapmak isteyen yatırımcılara, ilgili şirketlere ve diğer ilgili unsurlara yatırım kararı konusunda yardımcı olabileceği düşünülmektedir. Ayrıca bu çalışma, bağımsız değişken olarak farklı metaller ve değişik makroekonomik faktörler eklenmek suretiyle, aynı zamanda bağımlı değişkenlerin de farklılaştırılmasıyla yeni yapılacak araştırmalar için yol gösterici olabilir. 


\title{
EXTENDED ABSTRACT Analysis of Volatility Interaction between Gold, Silver and BIST Mining Index Returns with Diagonal VECH GARCH Model
}

\author{
* \\ Hüseyin Başar Önem \\ Isparta Uygulamal Bilimler University
}

While gold is a financial asset that has been used as an investment tool for a long time and attracts the attention of investors, silver has been attracting more and more investors' attention in recent years and is included in their portfolios. The interaction between financial investment instruments is increasing rapidly both in national economies and in global financial markets, and there is an important relationship between these instruments. In this study, it is aimed to determine the volatility spillover effect between gold and silver price returns and BIST Mining Index returns by econometric methods. For this purpose, after the introductory part, where the theoretical information of the study is given, the literature section, which includes the national and international literature review, which examines the relations between the returns of gold and silver prices and the returns of the BIST Mining Index, has been created. Then, the method to be used in the analysis was mentioned, and finally the study was completed with the research findings and the conclusion part.

In the study, which investigates the interaction and transfer of volatility between the BIST Mining Index operating in Borsa Istanbul and the gold and silver price returns, the daily closing values of the relevant indices for the periods 01.02.2017-01.02.2021 were used.

For this purpose the daily prices of gold and silver were obtained from the Central Bank EVDS (Electronic Data Distribution System), and the BIST mining index prices were obtained from the Finnet 2000 Plus database. In addition, return series of all variables were created.

When the descriptive statistics of the returns of the price indices of gold, silver and BIST Mining Index are examined, it is seen that gold, silver and BIST Mining Index have an average very close to zero. 
Standard deviation values were $135 \%$ for gold returns, $230 \%$ for silver returns and 355\% for BIST Mining Index returns.

In order for the variables used in the study to be stationary, unit root tests are performed. If a data contains a unit root, it means that the data is not stationary. According to Augmented Dickey-Fuller unit root test results, it is seen that gold, silver and BIST Mining Index variables are stationary at level values. After the unit root test, the appropriate lag lengths of the series were determined according to the Akaike information criterion, and the appropriate lag lengths of the Gold and BIST Mining Index were determined as 2 and the appropriate lag lengths of the Silver and BIST Mining Index were determined as 1.

According to the results of the Diagonal VECH GARCH model estimated for the returns of the Gold and BIST Mining Index, the parameters $C(1,1), C(2,1), C(2,2)$ represent a fixed number. Parameters $A(1,1)$ and $\mathrm{G}(1,1)$ explain the volatility of gold prices, and since both of these parameters are significant at the $5 \%$ confidence level, when the coefficients are summed, the result is 0.98 . This result, which is very close to the number 1 , shows that there are intense volatility clusters in gold price returns. In addition, volatility in gold prices has permanent and continuous effects. $A(2,2), G(2,2)$ parameters explain the volatility of the BIST Mining Index, and since both of these parameters are significant at the $5 \%$ confidence level, the result is 0.96 when the coefficients are summed. This result, which is very close to 1 , shows that there are intense volatility clusters in the BIST Mining Index returns. In addition, volatility has permanent and continuous effects in the BIST Mining Index. $A(2,1)$, $G(2,1)$ parameters also measure the effect of the volatility of gold price returns on the BIST Mining Index volatility. According to the results of the related table, the $\mathrm{A}(2,1)$ parameter is meaningless at the $5 \%$ confidence level, and the $\mathrm{G}(2,1)$ parameter is significant. The coefficient of the $\mathrm{G}(2,1)$ parameter is -0.88 , and according to this result, a $1 \%$ shock that increases the volatility of gold price returns reduces the BIST Mining Index volatility by $0.88 \%$ on the next trading day. Accordingly, there is a volatility interaction from gold prices to BIST Mining Index.

According to the results of the Diagonal VECH GARCH model estimated for the Silver and BIST Mining Index returns, the parameters $C(1,1), C(2,1), C(2,2)$ represent a fixed number. Parameters $A(1,1)$ and 
$\mathrm{G}(1,1)$ explain the volatility of silver price returns, and since both of these parameters are significant at the $5 \%$ confidence level, when the coefficients are summed, the result is 0.98 . This result, which is very close to the number 1 , shows that there are intense volatility clusters in silver price returns. In addition, volatility has permanent and continuous effects on the returns of silver prices. $A(2,2), G(2,2)$ parameters explain the BIST Mining Index volatility and since both of these parameters are significant at the 5\% confidence level, when the coefficients are summed, the result is 0.96 . This result, which is very close to the number 1 , shows that there are intense volatility clusters in the BIST mining index returns. In addition, volatility has permanent and continuous effects in the BIST Mining Index. $A(2,1), G(2,1)$ parameters also measure the effect of volatility of silver price returns on BIST Mining Index volatility. According to the results of the relevant table, the $\mathrm{A}(2,1)$ parameter is meaningless at the $5 \%$ confidence level, and the $\mathrm{G}(2,1)$ parameter is significant. The coefficient of the $G(2,1)$ parameter is -0.65 , and according to this result, a $1 \%$ shock that increases the volatility of silver prices returns reduces the BIST Mining Index volatility by $0.65 \%$ on the next trading day. Accordingly, there is a volatility interaction from silver prices to BIST Mining Index.

It is thought that the results obtained in the study can help investors who hold BIST Mining Index stocks and want to invest, related companies and other relevant elements in their investment decision. In addition, this study can be a guide for new researches by adding different metals and different macroeconomic factors as independent variables, and also by differentiating the dependent variables.

\section{Kaynakça / References}

Aijaz, U., Faisal, M. ve Meraj, S. (2016). Impact of oil and gold prices on stock market index. Journal of Business Strategies, 10(2), 69-84.

Baig, M. M., Shahbaz, M., Imran, M., Jabbar, M. ve Ain, Q. U. (2013). Relationship between gold and oil prices and stock market returns. Acta Universitatis Danubius, 9(5), 28-39. 
Başarır, Ç. (2019). Altın ve hisse senedi getirileri arasindaki nedensellik ilişkisi: Türkiye örneği. Trakya Üniversitesi Sosyal Bilimler Dergisi, 21(2), 475-490.

Bhunia, A. (2013). Cointegration and causal relationship among crude price, domestic gold price and financial variables: An evidence of BSE and NSE. Journal of Contemporary Issues in Business Research, 2(1), 1-10.

Bozkurt, H. (2009). M-GARCH modellerinin karşılaştırmalı analizi. Kocaeli Üniversitesi Sosyal Bilimler Enstitüsü Dergisi, 18, 126 - 145.

Cicioğlu, Ş., Eraslan, B. ve Torun, P. (2018). Türkiye'de altın fiyatlarını belirleyen faktörler. Journal of Human Sciences, 15(3), 1551-1560.

Ciner, C. (2001). On the long run relationship between gold and silver prices a note. Global Finance Journal, 12, 299 - 303.

Deniz, D., Okuyan, H. A. ve Sakarya, Ş. (2018). Kıymetli madenlerin portföy çeşitlendirme katkısı: BİST uygulaması. Mehmet Akif Ersoy Üniversitesi İktisadi ve İdari Bilimler Fakültesi Dergisi, 5(2), 366-382.

Elmastaş, Gültekin, Ö. ve Aktürk Hayat, E. (2016). Altın fiyatını etkileyen faktörlerin VAR modeli ile analizi: 2005-2015 dönemi. Ege Akademik Bakış, 16(4), 611-625.

Engle, R. F. ve Kroner, K. F. (1995). Multivariate simultaneous generalized ARCH. Econometric Theory, 11, 122-150.

Erdoğan, S. ve Bozkurt, H. (2009). Türkiye'de cari açığın belirleyicileri: MGARCH modelleri ile bir inceleme. Maliye Finans Yazıları, 23(84), 135-172.

Erol, A. F. ve Aytekin, S. (2020). Altın fiyatlarını etkileyen faktörlerin nedensellik analizi ile incelenmesi. International Congress of Management, Economy and Policy Proceedings Book, (ICOMEP'20), 77-89.

Eyüboğlu, K. ve Eyüboğlu, S. (2016). Metal fiyatları ile BİST-madencilik endeksinde işlem gören hisse senetleri arasındaki ilişkinin test edilmesi. Selçuk Üniversitesi Sosyal Bilimler Enstitüsü Dergisi, 36, 130-141.

Gazel, S. (2018). Değerli metaller ve makroekonomik değişkenler: Türkiye için bir Fourier eşbütünleşme testi uygulaması. Yönetim ve Ekonomi: Celal Bayar Üniversitesi İktisadi ve İdari Bilimler Fakültesi Dergisi, 25(2), 527-542.

Gopal, S. ve Munusamy, J. (2016).Causal relationship between gold, crude oil \& us dollar rates and S\&P BSE 100 in India: An experimental study. International Journal of Financial Management Volume, 6(2), 4150. 
Gökalp, B. T. (2019). Hisse senedi getirileri ile tüketici güven endeksi arasındaki ilişki: Diyagonal Vech modeli üzerinden bir değerlendirme. Ekonomi, Politika ve Finans Araştırmaları Dergisi, 4(1), 139-150.

Harper, A., Jin, Z., Sokunle, R. ve Wadhwa, M. (2013). Price volatility in the silver spot market: an empirical study using Garch applications. Journal of Finance and Accountancy, 1(1), 1-11.

Karabacak, M., Meçik, O. ve Genç, E. (2014). Koşullu değişen varyans modelleri ile BISTT 100 endeks getirisi ve altın getiri serisi volatilitesinin tahmini. Uluslararası Alanya İşletme Fakültesi Dergisi, 6(1), 79-90.

Mahato, P.K. ve Attar, V. (2014). Prediction of gold and silver stock price using ensemble models. IEEE International Conference on Advances in Engineering \& Technology Research, Dr. Virendra Swarup Group of Institutions, Unnao, India, 1-4.

Patel, S. (2012). The effect of macroeconomic determinants on the performance of the Indian stock market. NMIMS Management Review, XXII, 117-127.

Senaviratna, N. A. M. R. ve Cooray, T.M.J.A. (2017). Forecasting gold prices in Sri Lanka using generalized autoregressive conditional heteroskedasticity approach. International Research Journal of Natural and Applied Sciences, 4(7), 99-110.

Shaique, M., Aziz, A. ve Herani, G. M. (2016). Impact of gold prices on stock exchange market: A case of Karachi stock exchange market of Pakistan. International Journal of Accounting and Economics Studies, 4(1), 6063.

Songül, H. (2010). Otoregresif koşullu değişen varyans modelleri: Döviz kurlarn üzerine uygulama. Uzmanlık Yeterlilik Tezi. TCMB Araştırma ve Para Politikası Genel Müdürlüğü, Ankara, 1-68.

Sverdrup, H., Koca, D. ve Ragnarsdottir, K.V. (2014). Investigating the sustainability of the global silver supply, reserves, stocks in society and market price using different approaches. Resources, Conservation and Recycling, 83, 121-140.

Şencan, İ. (2017). BİST altın endeksi oynaklığı analizi ve performans ölçümü. Maliye Finans Yazıları, 107, 9-24.

Vveinhard, J., Streimikiene, D., Ahmed, R. R., Ghauri, S. P, ve Ashraf, M. (2017). Asymmetric influence of oil and gold prices on Baltic and South Asian stock markets: Evidence from Johansen cointegration and ARDL approach. Acta Montanistica Slovaca, 22(4), 422-438. 
Yaman, S.ve Korkmaz, T. (2020). Döviz kurları ile BİST turizm endeksi getirileri arasındaki volatilite yayılım etkisinin belirlenmesi. Business and Economics Research Journal, 11(3), 681-702

https://www.finnet2000.com/f2000plus/EndeksAnaliz/Endeks/GecmiseDonukKapan islar/XMADN 25.02.2021

https://evds2.tcmb.gov.tr/ 15.02.2021

\section{Kaynakça Bilgisi / Citation Information}

Önem, H. B. (2021). Altın, gümüş ile BİST madencilik endeksi getirileri arasındaki volatilite etkileşiminin diagonal VECH GARCH Modeliyle analizi. OPUS-Uluslararası Toplum Araştırmaları Dergisi, 18(43), 6220-6240. DOI: 10.26466/opus. 905547. 